\title{
Importance of Sand Grading on the Compressive Strength and Stiffness of Lime Mortar in Small Scale Model Studies
}

\author{
Abbagana Mohammed1*, Tim G. Hughes"\#, Aliyu Abubakar1 \\ ${ }^{1}$ Department of Civil Engineering, Abubakar Tafawa Balewa University, Bauchi, Nigeria \\ ${ }^{2}$ Cardiff University, Cardiff, UK \\ Email: *agmohammed@atbu.edu.ng
}

Received 8 November 2015; accepted 1 December 2015; published 4 December 2015

Copyright (C) 2015 by authors and Scientific Research Publishing Inc.

This work is licensed under the Creative Commons Attribution International License (CC BY). http://creativecommons.org/licenses/by/4.0/

(c) (i) Open Access

\begin{abstract}
Mortars provide the continuity required for the stability and exclusion of weather elements in masonry assemblies. But because of the heterogeneity of the mortar, its mechanism of behaviour under different load effects is dependent on the properties of the constituents of the mortar. The aim of paper is to determine the effect sand grading for various cement-sand-lime mortar designations (BS) and strength classes (EC) on the compressive strength and stiffness of mortar. Two silica sands; HST 95 and HST60 were used to make mortars in three strength classes: M2, M4 and M6, corresponding to mortar designations iv, iii and ii respectively. The results show that mortar made with the HST60 sand (coarser grading) usually resulted in mortar with a higher compressive strength and stiffness. The One Way ANOVA analysis of both compressive strength and stiffness at a significance level of $5 \%$ on the effect of sand grading on the two parameters also shows that they are both significant. There is also strong evidence of a linear correlation between the stiffness and compressive strength. The results indicate that in order to replicate full scale behaviour of masonry at model scales, the grading of fine aggregate in the models should be similar so as to properly model full scale behavior.
\end{abstract}

\section{Keywords}

Lime-Mortar, Sand Grading, Strength, Stiffness, Masonry, Model

\section{Introduction}

Masonry is a composite material, with the constituents having distinct strength and deformation characteristics.

\footnotetext{
*Corresponding author.

"Retired professor of civil engineering.
}

How to cite this paper: Mohammed, A., Hughes, T.G. and Abubakar, A. (2015) Importance of Sand Grading on the Compressive Strength and Stiffness of Lime Mortar in Small Scale Model Studies. Open Journal of Civil Engineering, 5, $372-378$. http://dx.doi.org/10.4236/ojce.2015.54037 
However, even though masonry has been used for thousands of years it is not well understood as it should be, because of the varying properties of its components as well as its failure mechanisms.

Mortars are used to bed and join masonry units giving them the continuity required for stability and exclusion of weather elements [1]. The proportion of the different constituents is usually determined by how the masonry is to be used, which is governed by the strength requirement of the application, degree of resistance to movement required, degree of frost resistance and rain penetration required etc.

Because mortar is not a homogeneous material, the mechanics of its behaviour under load are dependent on a variety of factors that influence each of its constituent elements. This paper aims to investigate the effect of sand grading for varying mortar designation on the mechanical properties of mortar like stiffness and compressive strength as it relates to small scale model studies. It presents part of a research programme looking at the behaviour of brickwork at prototype (full scale) and model scales [2]. This necessitated carrying out various tests on the different mortars used for the prototype and model scale tests.

The main agent responsible for the setting and strength development of cement mortars is the cement hydration process. Consequently the higher the cement content in mortar, the higher its strength. But because adequate cement hydration only takes place in the presence of sufficient water, the water/cement ratio of mortar becomes one of the most important factors that affect the compressive strength of mortars [3].

There are many parameters that influence mortar strength apart from the water/cement ratio and they include; cement volume, workability and sand grading. The effect of sand grading on the compressive strength has shown a higher strength yield in mortars with coarse sands. While the effect of sand grading on the tensile bond properties of mortars has been discussed by Anderson and Held [4], who found that the finer the grading of sand, the lower the bond strength of the masonry. This suggests that, since very fine sands have to be used in relatively small brickwork models because of the thin joints, the bond strengths of such models may show lower bond strengths to a comparable prototype because of this reason. And generally the higher the cement content of mortar the stronger is the bond while the converse is true for the water to cement ratio.

The stiffness properties of mortar are also important because they greatly influence the stiffness properties of brickwork as well as its strength [1]. The stress/strain relationship in mortars usually shows distinct plastic characteristics.

\section{Materials and Methods}

\subsection{Materials}

In the selection of an appropriate mortar for the tests, it was intended that a mortar that best compares to what is in use currently and in the past for masonry structures would be most suitable. The first consideration was whether to use a cement-sand mortar or cement-sand-lime mortar. Traditionally lime has been used in mortar to improve its workability and water retention properties. It was thought that both of these properties were desirable considering possible difficulties in adequately placing mortar in the bed joints of the model specimens and rapid suction of water from the model bed joints because of their small thickness. Consequently, cement-sandlime mortar was adopted for the tests.

Three types of sand were used in this research. Ordinary building sand was used for tests involving full scale specimens while Congleton HST95 and HST60 silica sands were used for the model scale tests. In order to ensure the same sands were used throughout the study, all the sands were bought in one batch and of sufficient quantity to last the duration of the programme. The grading curves for the model sands and the ordinary building sand are shown in Figure 1, it shows that HST 60 sand and the building sand lie within the grading limits of the code, but nearer the fine limit. The building sand is just coarser than the HST 60 sand. While the other model sand, HST 95, has a grading that is finer than the fine limit set by the code. The grading of all the sands shows that they are within the limits set by BS EN 13139:2002 [5] for aggregates used in mortar.

The cement used conforms to BS EN 197-1:2000 [6]. It was acquired in different batches in order to ensure that the fresh qualities of the cement needed for strength build up are maintained during the duration of the testing programme. Hydrated lime which conforms to BS EN 459-1:2001 [7] was acquired in one batch and used throughout.

Three mortar designations according to BS 5628; ii, iii and iv were used for the silica sands (used for the small scale model tests) while the ordinary building sand was used in making just one type of designation iii mortar for the full scale tests. Details of the different mortars used for the study are summarised in Table $\mathbf{1}$. The 


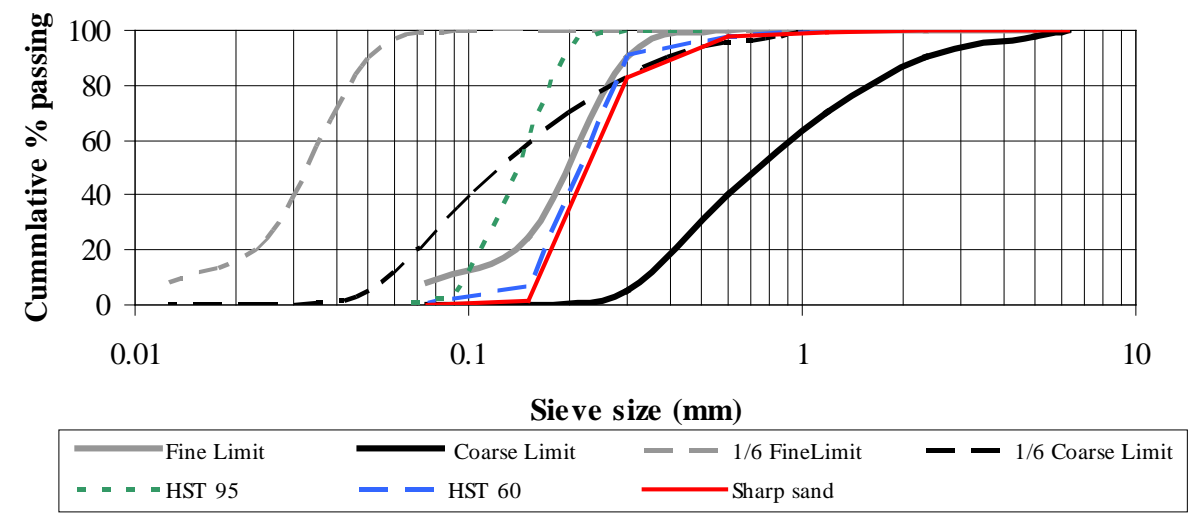

Figure 1. Grading curves for prototype and model sands within the BS limits.

Table 1. Properties of prototype and model mortars (COV in brackets).

\begin{tabular}{|c|c|c|c|c|c|c|c|}
\hline & HST95ii & HST95iii & HST95iv & HST60ii & HST60iii & HST60iv & MP \\
\hline Mortar Designation & ii & iii & iv & ii & iii & iv & iii \\
\hline Strength Class & M6 & M4 & M2 & M6 & M4 & M2 & M4 \\
\hline Vol. Proportions & $1: 1 / 2: 4$ & $1: 1: 6$ & $1: 2: 9$ & $11 / 2: 4$ & $1: 1: 6$ & $1: 2: 9$ & 1:1:6 \\
\hline W/c Ratio & 1.25 & 1.8 & 2.58 & 1.11 & 1.41 & 2.20 & 1.55 \\
\hline Comp. Str. N/mm ${ }^{2}$ & $12.9(6.8)$ & $8.0(3.7)$ & $3.8(4.8)$ & $20.7(4.1)$ & $11.7(6.6)$ & $6.0(0.6)$ & $4.4(6.8)$ \\
\hline Modulus of Elasticity & $12,900(7.9)$ & $6500(8.7)$ & $4500(12.7)$ & $17,000(2.96)$ & $12,500(5.22)$ & $6800(5.51)$ & $6300(17.8)$ \\
\hline Poisson's Ratio & 0.10 & 0.10 & 0.09 & 0.12 & 0.11 & 0.10 & 0.12 \\
\hline
\end{tabular}

strength class is the new nomenclature used in the Eurocode 6 (EC 6) to differentiate the mortar types. Strength class M6, M4 and M2 correspond to mortar designations (ii), (iii), and (iv) respectively. The batching for the constituents of dry mortar was carried out in accordance with the guidance given in BS 4551 [8] for the batching by weight of the three chosen mortar designations.

\subsection{Methods}

Compressive strength and modulus of elasticity test.

The procedure outlined in BS EN 1015-11:1999 [9] were followed in testing the specimens. The test was carried under load control at a rate within the range of $0.06-0.1 \mathrm{kN} / \mathrm{s}$. Three prisms measuring $75 \times 75 \times 200 \mathrm{~mm}$ were used for determining the elastic properties of the prototype and model mortar modulus of elasticity tests as well as their compressive strengths. Four LVDT's were attached to each specimen as described for the brick specimens. The specimens were tested through two loading cycles of up to a third of the expected maximum load for some of the tests, but most of the tests were carried out without load cycling after it was seen that there was no noticeable difference in the loading and unloading cycles in the earlier tests. All the stiffness calculations were determined at a third of the maximum stress reached as a secant modulus.

\section{Results and Discussion}

Typical failure of the mortar specimens was by shear cracks in the direction of loading. This tended to be triangular in shape originating from the sides of the specimen at the top slanting inwards, towards the centre at mid height and diverging again to the sides of specimen at the bottom. The final outcome of this is a pyramidal shaped mass at failure considered to be due to the platen restraint.

\subsection{Compressive Strength}

The average value of the compressive strength for different batches of 1:1:6 prototype mortars, (MP mortar) was 
4.4 N/mm², as seen from Table 1, which gives a summary of mortar test results. This value of compressive strength is higher than the minimum compressive strength of $3.6 \mathrm{~N} / \mathrm{mm}^{2}$ as stipulated in BS 5268 [10] for mortar designation (iii), which is an indication that the batching, mixing and curing conditions used were appropriate for the attainment of the specified minimum strength.

From Figure 2, which shows the variation of model mortar compressive strength as the mortar strength class is increased, it is seen that mortars made with HST 60 sand consistently had higher compressive strengths than those made with HST 95 sand. The strength class was substituted for the mortar designations in the X-axis as it better illustrates the increase in strength.

As expected it can be seen from Figure 2 that the relationship between compressive strength and strength class is a linear relationship. For designation ii, (class M6), there is a $60 \%$ difference between the compressive strength of the M60 and M95 mortars. While for designation iv (class M2), there is also a similar difference of about 58\%. Because of the coarser grading of the HST 60 sand, it has higher a bulk density and thus a lower water to cement (w/c) ratio than an equivalent weight of HST 95 sand, which subsequently increases the compressive strength of M60 mortars. The wider divergence at higher mortar grades could be attributed to the greater quantity of cement available for making a more cohesive mix in the case of HST 60 mortar, which has coarser grading of sand. Therefore there is better cohesion between the coarse sand grains and finer cement grains. An investigation into the effects of grading on mortar properties by Anderson and Held [4] also yielded similar results; the sand with coarsest grading within the BS EN 13139 [5] limit gave higher compressive strength as a result of the lower w/c ratio.

Since the prototype sands are coarser than the model sands, there is a possibility that full scale tests could have higher mortar strength. However the influence of this on masonry strength might not be very significant as suggested by Hendry [11]; that halving of mortar cube strength only results in a $12 \%$ reduction in masonry strength for a medium strength brick. But the different grading of the sands could still have an effect on flexural bond strength and shear bond strength tests which are more susceptible to changes in the grading characteristics of the sand in the mortar as reported by Anderson and Held [4].

Table 2 shows a One Way ANOVA analysis of all the strength results at a significance level of $5 \%$. From the table it is clear that there is significant difference in the means of the compressive strengths judging from the very low value of $P$, thus implying that there is a real effect of the different sand gradings on mortar strength.

The variation of compressive strength with w/c ratio as shown in Figure 3 shows a decrease in compressive strength with increasing w/c ratio. It is also seen from the plot that at about a compressive strength of $3.5 \mathrm{~N} / \mathrm{mm}^{2}$ (grade iii mortar) the two mortars have the same value of w/c ratio of around 2. The plot also shows that the mortars with coarser sand (M60) are affected more by changes in w/c ratio than mortars with finer sand (M95)

M60 and 95

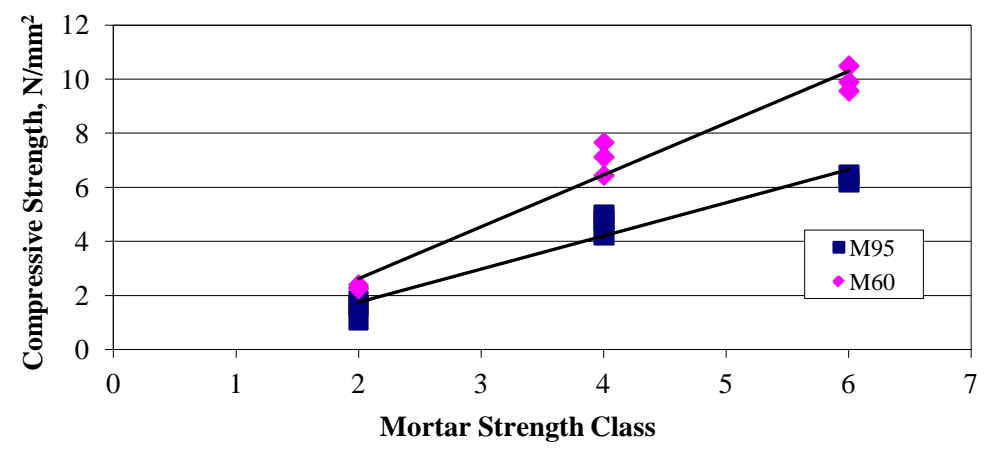

Figure 2. Variation of compressive strength with strength class for model mortars.

Table 2. Properties of prototype and model mortars (COV in brackets).

\begin{tabular}{cccc}
\hline Mortar Designation & Strength Class & P-Value & Remarks \\
\hline ii & M6 & 0.002 & Significant \\
iii & M4 & 0.005 & Significant \\
iv & M2 & 0.021 & Significant \\
\hline
\end{tabular}




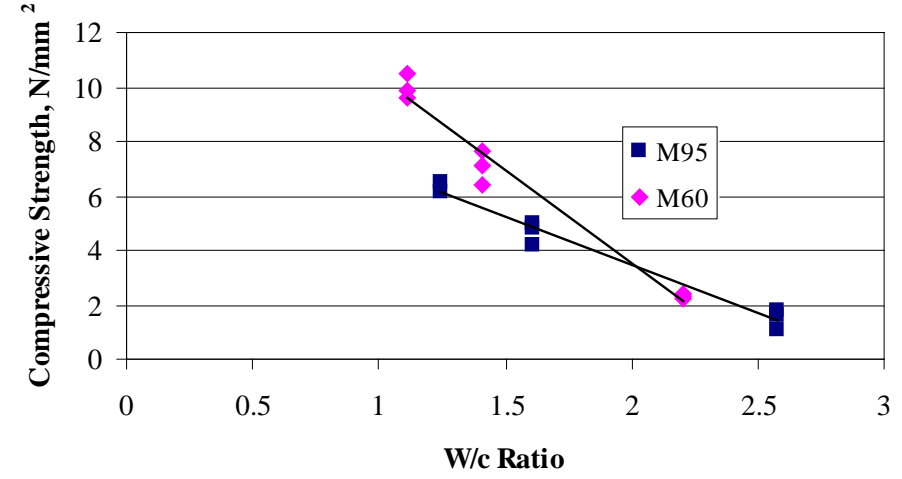

Figure 3. Variation of compressive strength of model mortars with w/c ratio.

mortars. This implies that the prototype tests could be more susceptible to changes in the w/c ratio than the model tests because of the coarser sands in the former.

\subsection{Stiffness}

It is seen in Figure 4 and Figure 5, which compare the stress/strain curves for the axial strain and lateral strain respectively, that the M60-ii and M95-ii mortars were the stiffest and showed a more brittle response than the less stiff M95-iv and M60-iv. However from Table 1, the stiffness of M60-iv and MP-iii were found to be similar even though MP-iii is a designation (iii) mortar.

From the stiffness/strength plot in Figure 6 and the stiffness/strength class plot in Figure 7, it is seen that there is a much greater difference in the stiffness between the strength classes in the M60 mortar than in the M95 mortars. For instance there is a 51\% percentage increase in stiffness between M95-iv and M95-ii, while the percentage increase in stiffness between M60-iv and M60-ii is 150\%. This shows that the coarser grading of the sand in the M60 mortars is more receptive to increase in cement content as discussed earlier. Across strength classes, it is seen that for the M2 strength class the mean M60 mortar stiffness is $2300 \mathrm{~N} / \mathrm{mm}^{2}$ higher than the corresponding M95 mortar stiffness. While for M6 strength class, the mean M60 mortar stiffness is $4100 \mathrm{~N} / \mathrm{mm}^{2}$ more than the corresponding M95 mortar stiffness. This indicates that even for suitable model sands, the stiffness and strength properties for the same designation of mortar could be different. The stiffness of MP-iii was determined to be $6300 \mathrm{~N} / \mathrm{mm}^{2}$; which is about 3\% less stiff than the M95-iii mortar and $86 \%$ less stiff than M60-iii mortar.

The One Way ANOVA analysis of all the stiffness results at a significance level of 5\% is shown in Table 3 . It reveals that there is a significant difference in the means of the stiffness as evidenced in the low value of $P$, thus suggesting that there is a real effect of the different sand gradings on mortar stiffness.

Therefore, when modelling prototype behaviour at model scale, the grading of the model sand should be similar to that of the prototype even though the average grain size is smaller.

\subsection{Stiffness/Strength Correlation}

The stiffness/strength plot in figure shows a very good linear correlation between stiffness and compressive strength for both M95 and M60 mortars. The regression equation for the M95 and M60 mortars are shown in Equations (1) and (2) respectively. The respective values of the R2 are displayed on the chart. From the values of the R2 for both mortar types, there is strong evidence of a linear correlation between the stiffness and compressive strength.

$$
\begin{array}{r}
Y=653 x+3860(\text { M60 Mortar }) \\
Y=958 x+402(\text { M95 Mortar })
\end{array}
$$

\section{Conclusion}

The results show the importance and effect of sand grading on the strength and stiffness of mortar even for sands 


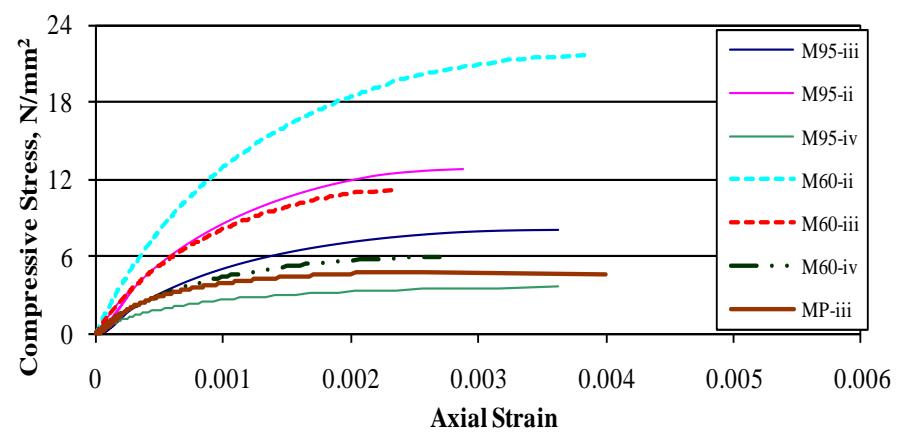

Figure 4. Comparison typical stress/axial strain plot for prototype and model mortars.

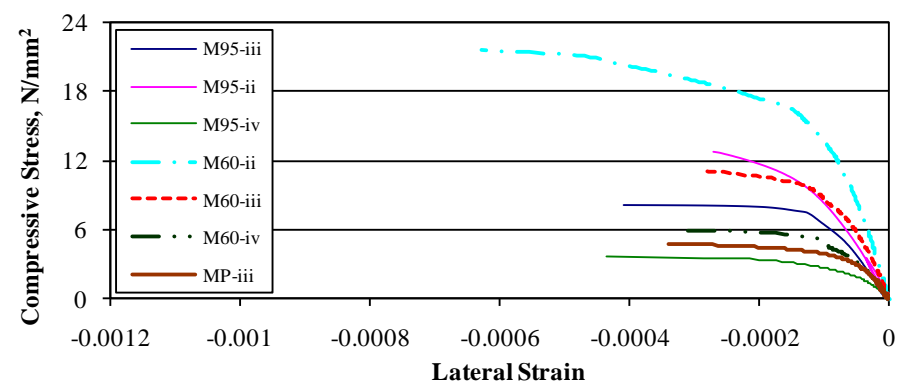

Figure 5. Comparison of typical stress/lateral strain plot for prototype and model mortars.

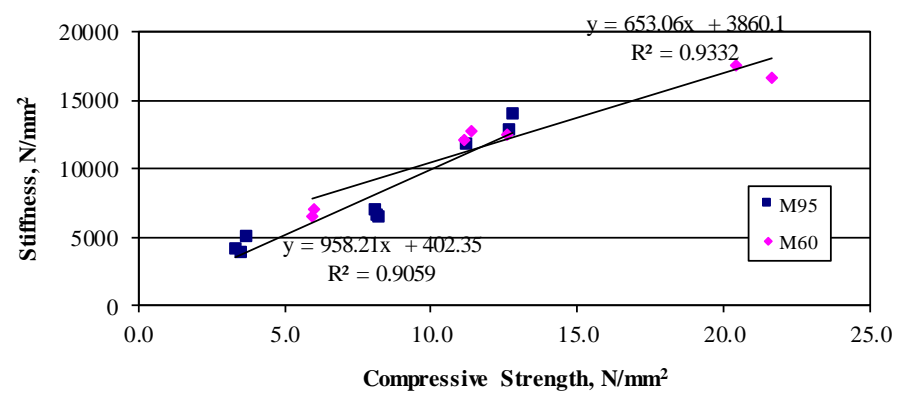

Figure 6. Variation of stiffness with strength for model mortars.

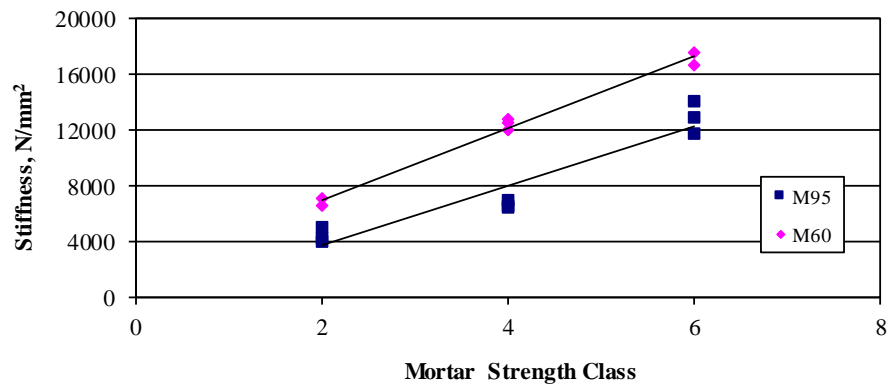

Figure 7. Variation of stiffness with strength class for model mortars.

Table 3. The P-values of the mortar tests showing the effect of sand grading on mortar stiffness at significance level of 5\%.

\begin{tabular}{ccccc}
\hline Mortar Designation & Strength Class & P-Value & Remarks \\
\hline ii & M6 & Significant & 0.019 & 0.000 \\
iii & Significant & 0.015 & Significant \\
iv & M2 & & 0.000 \\
\hline
\end{tabular}


with similar grain sizes. It revealed that mortar made with the HST60 sand (coarser grading) usually resulted in mortar with a higher compressive strength and stiffness. The One Way ANOVA analysis of both compressive strength and stiffness at a significance level of $5 \%$ on the effect of sand grading also shows that there is a significant difference in their means, implying that there is a real and discernible effect of the sand grading on both parameters. There is also a strong evidence of a linear correlation between the stiffness and compressive strength. Accordingly, in order to replicate full scale behaviour of masonry at model scales, the grading of fine aggregate in the models should be similar so as to properly model full scale behaviour.

\section{References}

[1] Lenczner, D. (1972) Elements of Loadbearing Brickwork. Pergamon Press, Oxford.

[2] Mohammed, A. (2006) Experimental Comparison of Brickwork Behaviour at Prototype and Model Scales. Cardiff University, Cardiff.

[3] Hendry, A.W., Sinha, B.P. and Davies, S.R. (1997) Design of Masonry Structures. 3rd Edition, E \& FN Spon, London. http://dx.doi.org/10.4324/9780203362402

[4] Anderson, C. and Held, L.C. (1986) The Effect of Sand Grading on Mortar Properties and the Tensile Bond of Brickwork Specimens. Proceedings of the British Masonry Society, No. 1, Stoke on Trent.

[5] British Standards Institution (2002) Aggregates for Mortar. (BSI), B.S.I., BS EN 13139:2002. British Standards Institution, London.

[6] British Standards Institution (2000) Cement. Composition, Specifications and Conformity Criteria for Common Cements. (BSI), B.S.I., BS EN 197-1:2000. British Standards Institution, London.

[7] British Standards Institution (2001) Building Lime. Definitions, Specifications and Conformity Criteria. (BSI), B.S.I., BS EN 459-1:2001. British Standards Institution, London.

[8] British Standards Institution (1998) Methods of Testing Mortars, Screeds and Plasters. (BSI), B.S.I., BS 4551: Part 1:1998. British Standards Institution, London.

[9] British Standards Institution (1999) Methods of Tests for Mortar for Masonry-Part 11: Determination of Flexural and Compressive Strength of Hardened Mortar. (BSI), B.S.I., BS EN 1015-11:1999. British Standards Institution, London.

[10] British Standards Institution (1995) Code of Practice for Use of Masonry: Part 2: Structural Use of Unreinforced Masonry. (BSI), B.S.I., BS 5628. British Standards Institution, London.

[11] Hendry, A.W. (1998) Structural Masonry. 2nd Edition, Macmillan Press, London. http://dx.doi.org/10.1007/978-1-349-14827-1 